\title{
PENGARUH FASILITAS TERHADAP KEPUASAN TAMU MENGINAP DI HANNAH HOTEL SYARIAH PAINAN
}

\author{
Wedi Andesta, Youmil Abrian \\ Progam Studi D4 Manajemen Perhotelan \\ Jurusan Pariwisata \\ Fakultas Pariwisata dan Perhotelan Universitas Negeri Padang \\ E-mail: wediandesta02@gmail.com
}

\begin{abstract}
This study aims to determine the effect of room facilities on guest satisfaction staying at Hannah Hotel Syariah Painan. This research is a quantitative descriptive study with a causal associative approach. The number of samples in this study were 82 samples. The sampling method is propotionate stratified random sampling. Data is collected by questionnaire using a Likert scale. The data analysis technique used in this study is descriptive analysis using simple linear regression analysis. The results of this study indicate that: (1) room facilities are in the good category 54.88\%, (2) guest satisfaction is in the excellent category 40.24\%, (3) there is a guest satisfaction value increased by 16.843 units, there is a positive influence and significant between room facilities to guest satisfaction staying at Hannah Hotel Syariah Painan. The R square value obtained is 0.174, this means that room facilities variables have an effect of $17.4 \%$.
\end{abstract}

\section{Keywords: Room Facilities and Guest Satisfaction}

\section{PENDAHULUAN}

Hotel adalah penyedia akomodasi berupa kamar-kamar di dalam suatu bangunan yang dilengkapi dengan jasa makan dan minum, kegiatan hiburan dan fasilitas lainnya secara harian dengan tujuan memperoleh keuntungan. Salah satu hotel berbintang tigadi kota Painan adalah Hannah Hotel Syariah Painan, hotel ini beralamat di Jl. Ilyas Yakub No. 25 Painan, IV Jurai, Pesisir Selatan. Fasilitas kamar adalah suatu sarana yang dapat memperlancar dan memudahkan tamu dalam menikmati layanan penginapan di kamar hotel sehingga kepuasan dan harapan tamu dapat tercapai. Fasilitas kamar yang disediakan sangat berpengaruh pada penilaian tamu dan pengguna jasa sehingga pada akhirnya nama baik atau citra hotel tersebut akan tetap terjaga.Jika fasilitas kamar dalam kondisi baik maka tentu tamu akan merasa puas. Sedangkan jika fasilitas kamar yang disediakan tidak memadai maka tamu yang berkunjung tidak akan merasa tidak puas. Oleh karena itu, fasilitas kamar perlu diperhatikan dan dipenihi sebagai mana mestinya dengan menerapkan strategi yang efektif oleh pihak pengelola hotel.

Permasalahan lain yang peneliti temukan yaitu setiap tipe kamar hotel belum menyediakan fasilitas seperti coffe table.Selanjutnya masalah lain yang ditemukan adalah pada fasilitas kamar mandi yang ada di Hannah Hotel Syariah, belum tersedianya fasilitas hairdryer dan berupa kaca rias pada tempat cuci tangan tempat gantungan handuk. Seharusnya pada kamar mandi disebuah hotel terdapat kaca dan juga tempat gantungan handuk. Pada saat penelitian dan atas dasar informasi yang didapat oleh peneliti guest supplies yang diberikan kepada tamu telah disediakan, tetapi untuk guest supplies yang tidak diberikan kepada tamu ada beberapa yang belum disediakan seperti: tisu toilet, gantungan baju, asbak, gelas minum, 
handuk muka, dan handuk tangan di dalam toiletnya. Dan tamu merasa tidak mendapatkan layanan yang baik dengan fasilitas kurang lengkap, tamu juga merasa bosan dang kurang nyaman karena fasilitas banyak yang kurang di Hannah Hotel Syariah maka penulis mengambiljudul: "Pengaruh Fasilitas Kamar Terhadap Kepuasan Tamu Menginap Di Hannah Syariah Hotel".

\section{METODE}

Penelitian ini digolongkan kepada penelitian deskriptif kuantitatif yaitu dengan metode assosiatif bentuk hubungan kausal, dengan jumlah sampel 82 orang.Metode yang digunakan adalah teknik jenuh atau total sampling. Dengan koresponden seluruh tamu yang menginap di Hannah Hotel Syariah. Pengumpulan data melalui angket, dengan bantuan skala likert.Teknik analisis penelitian ini menggunakan analisis regresi linier sederhana. Seterusnya uji persyaratan analisisnya adalah uji normalitas, homogenitas, linearitas serta pengujian hipotesis menggunakan regresi linear sederhana untuk melihat besaran pengaruh fasilitas kamar terhadap kepuasan tamu menginap.

\section{HASIL DAN PEMBAHASAN}

\section{Hasil}

\section{Analisis Deskriptif}

Berikut hasil penelitian tentang fasilitas kamar di kategorikan pada tabel berikut:

\section{Tabel 1. Distribusi Frekuensi Fasilitas Kamar}

\begin{tabular}{|c|c|c|c|}
\hline Kategori & Rentang Skor & Frekuensi & Persentase \\
\hline Sangat Baik & $>136.05$ & 30 & 36.58 \\
\hline Baik & $113.35<154.05$ & 45 & 54.88 \\
\hline Cukup & $90.96<<90.67$ & 7 & 8.53 \\
\hline Buruk & $67 ; 96<<90.67$ & 0 & 0 \\
\hline Sangat Bumk & $<67.96$ & 0 & 0 \\
\hline \multicolumn{2}{|c|}{ Total } & 82 & 100,00 \\
\hline
\end{tabular}

Berdasarkan tabel di atas, tentang deskripsi data variabel fasilitas kamar terdapat 36,58\% responden termasuk kategori sangat baik, $54,88 \%$ responden termasuk kategori baik, $8,530 \%$ responden termasuk kategori cukup, $0 \%$ responden termasuk kategori buruk, dan $0 \%$ responden termasuk kategori sangat buruk.

\section{Uji Persyaratan Analisis}

\section{1) Uji Normalitas}

Dengan hasil uji normalitas mengenai pengembangan karir dan kepuasan kerja dapat dikategorikan pada tabel dibawah ini.

Tabel 2. Hasil Uji Normalitas

\begin{tabular}{|c|c|c|c|}
\hline \multicolumn{4}{|c|}{ Ose-Sample Kolmogorov-Smirnov Test } \\
\hline & & Fasclitas Kamar & Kepuasan Tamu \\
\hline \multicolumn{2}{|l|}{$\mathrm{N}$} & 82 & 82 \\
\hline \multirow{2}{*}{$\begin{array}{l}\text { Normal } \\
\text { Parametersat }\end{array}$} & Mean & 13260 & 50.29 \\
\hline & Std Deviation & 10339 & 4.773 \\
\hline \multirow{3}{*}{$\begin{array}{l}\text { Most Extreme } \\
\text { Differences }\end{array}$} & Absolute & 109 & 115 \\
\hline & Positive & .109 & .053 \\
\hline & Negative & -057 & -084 \\
\hline \multicolumn{2}{|c|}{ Fest Statistic } & .109 & 115 \\
\hline \multicolumn{2}{|c|}{ Asymp Sig (2-tailed) } & $095^{\circ}$ & $080^{\circ}$ \\
\hline \multicolumn{4}{|c|}{ a. Test distribution is Normal. } \\
\hline \multicolumn{4}{|c|}{ b. Calculated from data. } \\
\hline \multicolumn{4}{|c|}{ c. Lilliefors Significance Cortection. } \\
\hline
\end{tabular}

Berdasarkan tabel di atas dapat diketahui bahwa Sig untuk fasilitas kamar dan kepuasan tamu berturut-turut adalah 0,95 dan 0,80 lebih besar dari 0,05 , sehingga dapat dikatakan bahwa data kedua variabel terdistribusi normal.

\section{2) Uji Homogenitas}

Dari hasil uji homogenitas mengenai pengembangan karir, dan kepuasan kerja dapat dikategorikan pada tabel dibawah:

Tabel 4. Hasil Uji Homogenitas

\begin{tabular}{|c|c|c|c|c|c|}
\hline \multicolumn{6}{|c|}{ ANOVA } \\
\hline \multicolumn{6}{|c|}{ Fasilitas Kamar } \\
\hline & Sum of Squares & df & Mean Square & F & Sig. \\
\hline Between Groups & 2695,447 & 20 & 134,772 & 1,379 & 169 \\
\hline Within Groups & 5962,272 & 61 & 97,742 & & \\
\hline Total & 8657,720 & 81 & & & \\
\hline \multicolumn{6}{|l|}{ Repuasan Tamu } \\
\hline & Sum of Squares & df & Mean Square & F & Sig \\
\hline Between Groups & 911,645 & 31 & 29,408 & 1,572 & 076 \\
\hline Within Groups & 935,331 & 50 & 18,707 & & \\
\hline Total & 1846,976 & 81 & & & \\
\hline
\end{tabular}

Berdasarkan hasil analisis uji homogenitas pada tabel diatas diperoleh nilai Sig fasilitas kamar adalah 0,169 dan 
kepuasan tamu adalah 0,076 dengan taraf signifikansi $>0,05$. Ini artinya nilai signifikansi data lebih besar dari taraf signifikansi. Sehingga dapat diambil kesimpulan bahwa data berasal dari populasi yang mempunyai varians yang sama atau data bersifat homogeny.

\section{3) Uji Linearitas}

Uji linearitas mengenai pengembangan karir, dan kepuasaan kerja dapat dikategorikan pada tabel berikut;

\section{Tabel 5. Hasil Uji Linearitas}

\begin{tabular}{|c|c|c|c|c|c|c|c|}
\hline \multicolumn{8}{|c|}{ A NOVA Table } \\
\hline & & & $\begin{array}{l}\text { Sum of } \\
\text { Squares }\end{array}$ & dI & $\begin{array}{l}\text { Mean } \\
\text { Square }\end{array}$ & F & $S_{i}$ \\
\hline \multirow{5}{*}{$\begin{array}{l}\text { Kepuasa } \\
\text { n tamus } \\
\text { faslitas } \\
\text { kames }\end{array}$} & \multirow{3}{*}{\begin{tabular}{|l} 
Betwe \\
en \\
Groap \\
5
\end{tabular}} & (Combined) & 911.645 & 31 & 29.408 & 1572 & .076 \\
\hline & & Lineanity & 321.226 & 1 & 321.226 & 17.172 & 000 \\
\hline & & $\begin{array}{l}\text { Deviation from } \\
\text { Linearity }\end{array}$ & 590.419 & 30 & 19.681 & 1.052 & 428 \\
\hline & \multicolumn{2}{|c|}{ Within Grovps } & 935331 & 50 & 18.707 & & \\
\hline & \multicolumn{2}{|l|}{ Total } & 1846.976 & 81 & & & \\
\hline
\end{tabular}

Berdasarkan hasil analisis uji linearitas pada tabel diatas, diperoleh nilai Deviation From Linearity adalah $0,428>0,05$. Ini artinya nilai kedua variabel mempunyai hubungan yang linear.

\section{c. Pengujian Hipotesis}

Tabel 6. Regresi Linear Sederhana

\begin{tabular}{|c|c|c|c|c|c|c|}
\hline \multicolumn{7}{|c|}{ Avova: } \\
\hline \multicolumn{2}{|c|}{ Model } & Sum of Squares & $\mathrm{Df}$ & Mean Square & F & Sig \\
\hline \multirow[t]{3}{*}{1} & Regression & 321.226 & 1 & 321.226 & 16.843 & $.000^{2}$ \\
\hline & Residual & 1525.750 & 80 & 19.072 & & \\
\hline & Total & 1846.976 & 81 & & & \\
\hline \multicolumn{7}{|c|}{ a. Dependent Variable: kepuasan tamu } \\
\hline \multicolumn{7}{|c|}{ b. Predictors (Constant), fasilitas kamar } \\
\hline
\end{tabular}

Berdasarkan hasil uji regresi linear diatas diperoleh nilai $\mathrm{F}$ hitung 16.843 dengan sig. $0,000<0,05$ artinya variabel $\mathrm{X}$ dapat menjelaskan variabel $\mathrm{Y}$ secara signifikan. Jadi variabel fasilitas kamar mempengaruhi variabel kepuasan tamu, maka Ha diterima dan Ho ditolak dan terdapat pengaruh yang positif dan signifikan antara fasilitas kamar dengan kepuasan tamu menginap di Hannah Hotel Syariah Painan.
Tabel 7. Hasil Uji Koefisien Regresi Variabel X Terhadap

\begin{tabular}{|c|c|c|c|c|c|c|}
\hline \multicolumn{7}{|c|}{ Coefficients ${ }^{2}$} \\
\hline \multirow{2}{*}{\multicolumn{2}{|c|}{ Model }} & \multicolumn{2}{|c|}{ Unstandardized Coefficients } & \multirow{2}{*}{\begin{tabular}{|l} 
Standardized \\
Coefficients \\
Beta \\
\end{tabular}} & \multirow[b]{2}{*}{$\mathrm{t}$} & \multirow[b]{2}{*}{ Sig. } \\
\hline & & B & Std. Error & & & \\
\hline \multirow[t]{2}{*}{1} & (Constant) & 24.752 & 6.242 & & 3.965 & 000 \\
\hline & fasilitas kamar & .193 & .047 & 417 & 4.104 & .000 \\
\hline
\end{tabular}

Berdasarkan tabel di atas di peroleh

persamaan sebagai berikut:

$\mathrm{Y}=\mathrm{a}+\mathrm{bX}=24,752+0,193 \mathrm{X}$

$\mathrm{Y}=\mathrm{a}+\mathrm{b} \cdot \mathrm{X}$

Dimana: Y: Kepuasan Tamu

$\mathrm{X}$ :Fasilitas Kamar

a. Konstanta

b. Koefisien Regresi

Maka dengan tingkat signifikan $0,000<$ 0,05 hal ini menunjukan fasilitas kamar berpengaruh terhadap kepuasan tamu dan dapat di jelaskan untuk setiap peningkatan fasilitas sebesar 1 satuan maka dapat meningkatkan kepuasan sebesar 0,193.

Tabel 8. Hasil Uji R Square Variabel $X$ Terhadap $Y$

\begin{tabular}{|l|l|l|l|l|}
\hline \multicolumn{4}{|c|}{ Model Summary } \\
\hline Model & R & R Square & Adjusted R Square & Std. Error of the Estimate \\
\hline 1 & $.417^{\mathrm{a}}$ & .174 & .164 & 4.36714 \\
\hline a. Predictors: (Constant), fasilitas kamar \\
\hline
\end{tabular}

Berdasarkan tabel di atas diperoleh nilai $R$ Square 0,174 artinya pengaruh variabel $\mathrm{X}$ terhadap variabel $\mathrm{Y}$ adalah sebesar $17,4 \%$. Sedangkan $82,6 \%$ dipengaruhi faktor lain yang tidak dibahas di penelitian.

\section{PEMBAHASAN}

\section{a. Kompetensi Kerja}

Berdasarkan hasil penilaian dari 30 orang sampel, maka variabel Kompetensi dapat dikelompokan sebagai berikut: 100\% responden termasuk kategori sangat baik, $0 \%$ responden termasuk kategori baik $0 \%$ responden termasuk kategori cukup, 0\% 


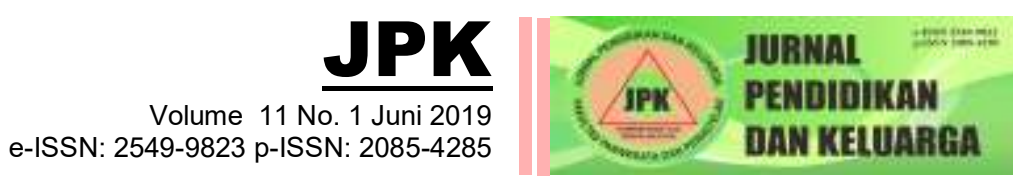

responden termasuk kategori buruk. $0 \%$ responden termasuk kategori sangat buruk. Artinya hampir seluruh karyawan Rocky Plaza Hotel Padang menilai kompetensi sangat baik.

\section{b. Kinerja Karyawan}

Berdasarkan hasil penilaian dari 82 orang sampel, maka variabel kepuasan tamu dapat dikelompokan sebagai berikut: 40,24\% responden termasuk kategori sangat baik, 20,73\% responden termasuk kategori baik. $24,39 \%$ responden termasuk kategori cukup, $14,63 \%$ responden termasuk kategori buruk, $0,0 \%$ responden termasuk kategori sangat buruk. Artinya penilaian terbesar pada kepuasan tamu di Hannah Hotel Syariah Painan masuk dalam kategori sangat baik. Walaupun demikian pada kategori cukup sebesar $24,39 \%$.

c. Pengaruh Fasilitas Kamar Terhadap Kepuasan Tamu Menginap di Hannah Hotel Syariah

Hasil penelitian menunjukan bahwasannya terdapat pengaruh yang positif dan signifikan antara fasilitas kamar terhadap kepuasan tamu menginap di Hannah Hotel Syariah, hal ini ditunjukan dengan hasil uji regresi sederhana yang telah dilakukan, diperoleh nilai $\mathrm{F}$ hitung 16.843 dengan signifikan $0,000<0,05$ artinya variabel $\mathrm{X}$ dapat menjelaskan variabel $\mathrm{Y}$ secara signifikan.

\section{PENUTUP}

\section{Kesimpulan}

Fasilitas Kamar di Hannah Hotel Syariah secara keseluruhan diperoleh 30 responden (36,58\%) dengan kategori sangat baik, 45 responden (54,88\%) dengan kategori baik, 7 responden (8,53\%) dengan kategori cukup.Kepuasan tamu menginap di Hannah Hotel Syariah Painan secara keseluruhan diperoleh 33 responden
(40,24\%) menyatakan sangat baik, 17 responden $(20,73 \%)$ menyatakan baik, 20 responden $(24,39 \%)$ menyatakan cukup, dan 12 responden $(14,63 \%)$ menyatakan buruk. Terdapat pengaruh yang positif dan signifikan antara fasilitas kamar terhadap kepuasan tamu menginap di Hannah Hotel Syariah Painan, hal ini ditunjukan dengan hasil uji regresi sederhana yang telah dilakukan, diperoleh nilai F 16,843 dengan sig $0.000<0.05$, sehingga dapat diambil kesimpulan bahwasannya Ha diterima dan $\mathrm{H} 0$ ditolak dan dapat diartikan terdapat pengaruh yang positif dan signifikan antara fasilitas kamar terhadap kepuasan tamu menginap di Hannah Hotel Syariah Painan. Nilai R square yang diperoleh sebesar 0,174 hal ini berarti variabel fasilitas kamar berpengaruh sebesar $17,4 \%$ terhadap kepuasan tamu menginap di Hannah Hotel Syariah dan $82,4 \%$ dipengaruhi oleh variabel lain yang tidak dibahas dalam penelitian ini.

\section{Saran}

Kepada manajemen hotel agar selalu memperhatikan kelayakan kualitas fasilitas kamar dan kekuranganya harus lebih ditingkatkan lagi, agar tidak adanya tamu yang merasa kurang puas terhadap fasilitas yang ada, misalnya mengadakan pembaruan dan penambahan fasilitas serta di sesuaikan standar hotel bintang***.

\section{DAFTAR PUSTAKA}

Nawawi, Hadari. 2006. Evaluasi dan Manajemen Kinerja di lingkungan Perusahaan dan Industri. Yogyakarta: Gajah Mada Univercity Press.

Suatno. \& Priansa, D. 2011. Manajemen SDM Dalam Organisasi Publik Dan Bisnis. Bandung: Alfabeta. 